\title{
A literatura romântica portuguesa sob o olhar de Álvares de Azevedo e Lopes de Mendonça: diálogos críticos
}

\author{
Natália Gonçalves de Souza Santos*
}

\section{Introdução $^{1}$}

Embora seja mais conhecido por sua produção poética e ficcional, tendo legado obras como Lira dos vinte anos (1853) e Macário (1855), a produção literária do escritor romântico Álvares de Azevedo compreende também quatro ensaios críticos. Esse conjunto é composto por "Alfredo de Musset: Jacques Rolla", "George Sand: Aldo o rimador", "Lucano" e "Literatura e civilização em Portugal". Assim como a maior parte de sua obra, esses textos também são de publicação póstuma, à exceção do primeiro deles, parcialmente estampado no periódico acadêmico Ensaios literários, em 1850. Para além dessa característica quase comum a todos esses textos, sua leitura evidencia a propensão do autor à prática da citação, o que possibilita a interligação das diversas discussões propostas por ele nos quatro ensaios a um amplo debate que se travava no periodismo literário internacional.

Mesmo que a relativa abundância de referências bibliográficas não seja, em meados do século XIX, um traço exclusivo de Álvares de Azevedo, ${ }^{2}$ fato é que essa prática já foi entendida como negativa por aqueles que se debruçaram sobre sua prosa ensaística. Brito Broca chega a dizer, por exemplo, que "os discursos de Álvares de Azevedo e seus esboços de estudos literários não passam de um cascatear insuportável de palavras” (1979, p. 320), concluindo que as incessantes citações feitas por ele revelam "uma cultura superficial, a única que seria compatível com tão curta existência” (1979, p. 98). É certo que o jovem bacharel em Direito

\footnotetext{
Doutoranda em Letras (Teoria Literária e Literatura Comparada) na Universidade de São Paulo (USP), São Paulo, SP, Brasil. E-mail: nataliasantosgs@gmail.com

1 Uma primeira versão deste texto foi apresentada como comunicação oral no VI Congresso NorteNordeste da Associação Brasileira de Professores de Literatura Portuguesa (ABRAPLIP), realizado em Natal (RN), em 2016.

2 No artigo "Literatura comparada", Antonio Candido refere-se ao intenso jogo de citações por parte dos críticos e de epígrafes por parte dos poetas, que permeava a nossa literatura oitocentista, assinalando uma espécie de "vocação comparatista espontânea e informal" (1993, p. 213) dos nossos escritores, que se respaldavam num "sentimento reconfortante de parentesco" com os escritores do cânone europeu (1993, p. 211).
} 
prezava, talvez em demasia, a incorporação de outros textos a seu próprio, o que, em diversas passagens, pode acarretar alguma obscuridade, já que aquilo que era claro à época, não o é à posteridade, notadamente quando os debates são extraídos de jornais e revistas em circulação no oitocentos, mais sujeitos à efemeridade.

Porém, o levantamento e a análise desse arcabouço teórico empregado por Álvares de Azevedo permite deslindar um rol de outras interlocuções travadas por ele, ademais daquelas que já são bastante conhecidas, caso de Victor Hugo, ${ }^{3}$ Byron, ${ }^{4}$ Alfred de Musset ${ }^{5}$ etc. Tal é o caso da que pretendemos analisar ao longo deste artigo e que se faz mais presente em "Literatura e civilização em Portugal". É aí que se pode observar um evidente diálogo crítico com Antônio Pedro Lopes de Mendonça (1826-1865), escritor português conhecido, notadamente, por seu trabalho no periódico lisboeta A Revolução de Setembro. A obra de Lopes de Mendonça citada por Álvares de Azevedo, os Ensaios de crítica e literatura (1849), é uma coletânea de artigos originalmente veiculada na referida revista e que, em 1855, sofre novas e importantes modificações, para ser publicada sob o título de Memórias de literatura contemporânea. Cumpre dizer que essa última versão da obra contém uma seção dedicada a autores estrangeiros, entre os quais o próprio Azevedo, já falecido a essa altura e que é bastante elogiado pelo crítico. Além disso, segundo Maria Eunice Moreira, essa é a primeira ocasião, em Portugal, na qual se trata em livro de autores do Romantismo brasileiro, já que, além de resenhar a Lira dos vinte anos, Mendonça faz também a crítica a Gonçalves Dias (2013, p. 72).

Ao menos durante a fase de publicação dessas duas coletâneas, é improvável que Lopes de Mendonça soubesse da leitura assídua que o poeta brasileiro fez do seu livro de 1849, já que o ensaio "Literatura e civilização em Portugal" é redigido, provavelmente, em 1850, e publicado somente em 1855. Nele, Azevedo tem por objetivo discutir a "marcha simultânea da civilização e poesia em Portugal" (AzEvEDo, 2000, p. 822-823). Assim, ele divide a história literária lusa em duas fa-

3 Antonio Candido, na seção "A crítica viva”, da Formação da literatura brasileira, afirma que entre os brasileiros, Álvares de Azevedo é o único a se valer de forma concreta da teoria dos contrastes de Victor Hugo, exposta no prefácio ao Cromwell (1827). Nesse sentido, Candido procura demonstrar o uso dessa teoria no ensaio sobre o poema "Rolla", de Alfred de Musset (CANDIDo, 2006, p. 673 e ss.).

4 Byron é um dos autores mais citados e emulados pelos escritores oitocentistas que circularam em meados do século XIX pela Academia de Direito de São Paulo. Cilaine Alves Cunha (1998), em O belo e o disforme: Álvares de Azevedo e a ironia romântica, e Vagner Camilo (1997), em Risos entre pares: poesia e humor românticos, apresentam um panorama dessa moda literária na capital paulista, analisando, cada um a sua maneira, o byronismo na poesia de Azevedo. Essa presença é estudada por outro viés, o da tradução literária, por Onédia Célia de Carvalho Barbosa que, no livro Byron no Brasil: traduções, discute a importância de Álvares de Azevedo enquanto divulgador e tradutor do lord inglês entre nós.

5 Em Astarte e a espiral: um confronto entre Álvares de Azevedo e Alfred de Musset, Maria Alice de Oliveira Faria (1973) faz uma comparação entre os dois autores e uma análise da tradução feita pelo brasileiro do poema "Rolla". Em nossa tese de doutorado, intitulada Um leitor inconformado: Álvares de Azevedo e o periodismo do século XIX (Santos, 2018), Azevedo e Musset são mais uma vez aproximados, desta feita pela perspectiva do ceticismo. 
ses: a heroica e a negra. A primeira corresponderia ao esplendor das conquistas e do império ultramarino, com apogeu no século XVI, e teria como principais representantes a obra épica de Camões e a tragédia Castro, de Antônio Ferreira. A segunda corresponderia à decadência desse mesmo império e seria representada pela lírica intimista e melancólica de Bocage.

\section{Diálogos transatlânticos}

Álvares de Azevedo se remete às opiniões de Mendonça em dois momentos da sua argumentação ao longo de "Literatura e civilização em Portugal": ao lamentar o suposto suicídio de Bocage e ao criticar negativamente parte da literatura romântica portuguesa produzida na altura de 1850 . Neste artigo, abordaremos esse último momento.

Não causaria espécie ao leitor do ensaio alvaresiano as afirmações de que Luís de Camões e Antônio Ferreira são "dois grandes vultos de poeta" (Azevedo, 20oo, p. 725), ou a de que "o Sr. J. B. A. Garrett não é só o primeiro poeta português do século, o digno par do erudito Sr. Alexandre Herculano mas também [...] é uma literatura" (200o, p. 721), tendo em vista que ambas se assentam num relativo consenso. Em contrapartida, a situação é outra quando se trata de João de Lemos, Mendes Leal, Pereira da Cunha ou José Freire de Serpa Pimentel, escritores que adentravam a cena literária em meados de 1840 , e não contavam com a chancela da crítica e/ou da tradição. Nesse sentido, pode-se dizer que os Ensaios de crítica e literatura aparecem num passo algo delicado da pequena história literária traçada no texto.

Todos citados por Azevedo, acrescidos de títulos de obras e brevíssimo comentário, este rol de nomes "provavelmente pouco ou nada dizem ao leitor ou ao espectador dos nossos dias" (Pires; ReIs, 1993, p. 146). No entanto, eles não poderiam ser excluídos de uma visada panorâmica da atualidade da literatura portuguesa. Torna-se, assim, oportuno eleger um crítico quase tão jovem quanto o próprio autor brasileiro para aventurar-se na interpretação da nova safra de escritores. Alguém que, além de companheiro e integrante da geração literária que despontava e produzia naquele momento, graças à sua profissão, encontrava-se em sintonia com aquilo que acabava de ser publicado.

Observa-se, assim, o esboço de um diálogo crítico que sugere, de certa forma, a manutenção das relações literárias entre Brasil e Portugal, algo que se torna ainda mais notável quando consideramos a acentuada aproximação da geração de Azevedo aos próceres do romantismo francês e inglês. Como procuraremos evidenciar neste artigo, a circulação transatlântica entre as academias de direito de São Paulo e Coimbra (a qual se ligam os nomes do ultrarromantismo português) era ainda considerável e, até um certo limite, mais sincrônica do que se poderia supor. Nesse sentido, pode-se dizer que, mesmo à sua revelia, Lopes de Mendonça 
atuou como uma espécie de passeur culturel entre as faculdades de direito de São Paulo e Coimbra, uma vez que, ao se ocupar da produção poética dos estudantes de seu entorno, projetou-a para além-mar e, ao comentar a Lira dos vinte anos, contribuiu, em terras lusas, para a construção do mito do jovem poeta estudante, morto prematuramente, que cerca a figura de Álvares de Azevedo. ${ }^{6}$

Por outro lado, ao se comparar o espaço textual que Azevedo dedica, em seu ensaio, ao cânone luso e aquele que reserva aos novos talentos, é possível observar uma clara desproporção. Isso pode ser entendido tanto como desconhecimento, já que mesmo Mendonça julga seu extenso trabalho como panorâmico, quanto como certo desmerecimento. Assim, uma quantidade relativamente grande de escritores é comentada em poucos parágrafos, que acabam se tornando algo atravancados, tendo em vista a quantidade de informações que o ensaísta brasileiro deseja transmitir. Além disso, tais escritores não perfazem uma fase específica da história lusa, caso de Camões e Ferreira, figuras do seu apogeu literário, e Bocage, escritor de uma etapa designada como decadente. Eles são introduzidos naquilo que Azevedo chama de preâmbulo, portanto, antes das fases, e de forma digressiva, enquanto o ensaísta comenta um outro assunto, causando no leitor a impressão de que esses escritores ainda não ocupariam um lugar específico.

No entanto, seria possível pensar que esse bloco textual poderia ser encaixado como continuação da fase negra de Portugal, não em termos de estrutura do ensaio, mas, sim, de continuidade literária. ${ }^{7}$ Afinal, no decorrer do século XIX, as condições socioeconômicas portuguesas apenas se agravaram, e a situação política, permeada por revoltas e golpes, também era delicada (GINZBURG, 1999, p. 22). Em meio a tal contexto, e de acordo com a lógica de simultaneidade social e literária proposta pelo ensaio, pode-se supor que a literatura daquele período não poderia ser grandiosa, fato que se confirma pela própria interpretação feita por Álvares de Azevedo. Diferentemente de Bocage, que conseguia dar vazão ao mal-estar de sua época por meio de uma poesia original e de qualidade (AZEVEDo, 200o, p. 737), ele considera que a literatura portuguesa mais moderna se apequenara, degenerandose na imitação servil dos próceres do Romantismo europeu, marcadamente do francês (AzEvedo, 20oo, p. 719). Tanto no poeta de Setúbal, quanto em Ferreira e Camões, o crítico brasileiro identifica uma série de apropriações de distintas tradi-

6 A consulta da obra A imprensa estudantil de Coimbra, de Manuel Alberto Carvalho Prata, permite identificar Álvares de Azevedo como colaborador de mais de um periódico acadêmico oitocentista de Coimbra, entre os quais O Átila (1863-1864), Revista de Coimbra (1865-1866) e Mosaico (1874-1875), o que significa dizer que seus poemas foram estampados nessas páginas, além de existirem menções a sua pessoa em tantas outras. Em estudo futuro, pretendemos nos ater exclusivamente à presença do autor brasileiro nesse meio jornalístico, procurando compreendê-la qualitativamente.

7 No artigo "Palpites dissonantes de brasileirismo em 'Literatura e civilização em Portugal'”, Cilaine Alves Cunha lança a hipótese de que esse texto alvaresiano pode ser entendido como paródia das periodizações literárias que se esboçavam no período (2001, p. 24). Nesse sentido, talvez se compreenda essa descontinuidade temporal detectada nesse passo do ensaio. 
ções literárias, o que dota aquilo que eles escreveram de uma perspectiva cosmopolita que lhe é muito cara e que ele não verifica na moderna literatura portuguesa.

Numa perspectiva mais ampla, nota-se que Mendonça também via a trajetória histórica de sua pátria como um movimento de declínio, cuja queda começava, a seu ver, em 1640, ano em que os portugueses se libertaram do domínio espanhol, ocasionando, segundo o jornalista, a substituição do ímpeto guerreiro e de conquista da nobreza pelo ócio cortesão, financiado pela exploração ultramarina. Assim, diz Lopes de Mendonça,

enquanto as outras nações se enriqueciam pela indústria, se moralizavam pelo trabalho, e se engrandeciam pelo talento, nós comíamos os despojos de nossas batalhas, reviamo-nos nos monumentos das nossas glórias, e a literatura depois de ter produzido os Lusíadas, vegetava apodrecida nos gongorismos do conde de Ericeira, e apenas se elevava nas obras de um jesuíta - o padre Antonio Vieira (1849, p. 14).

Álvares de Azevedo e Lopes de Mendonça aproximam-se, então, quanto à análise do turvo presente da história portuguesa. Aliás, cabe dizer que o percurso que parte de um apogeu e se encaminha a um declínio, configurando um percurso historiográfico sinuoso, não era opção incomum à época, sendo adotado também por Almeida Garrett, no Bosquejo da história da poesia e língua portuguesa (1826). Porém, mesmo não se eximindo de apontar aquilo que considera problemático na nova geração, Lopes de Mendonça elogia os ganhos que ela trouxe e crê que ela tem importante papel a desempenhar na vida social e literária do país (MENDONÇA, 1849, p. 3-4).

Não se pode dizer o mesmo a partir dos comentários feitos por Azevedo. Esquematicamente, ele pontua que a existência de uma imitação irrefletida dos grandes expoentes de uma escola literária é o cerne da literatura de má qualidade, e não apenas em Portugal, mas em qualquer tradição literária. É dela que decorrem o "sentimentalismo às vezes falso" (AzEvEDo, 200o, p. 718) e a "monotonia" (AzEvedo, 200o, p. 720) de determinadas tópicas, gerando um efeito em cadeia: à medida que se imita imagens e sensações desgastadas, porém ao gosto do público, não se atinge uma poesia condizente com a verdadeira expressão da subjetividade romântica.

Segundo Azevedo,

os chefes de sistema literário são mais por admirar e estudar que por copiar, Goethe lamentava-se dos seus imitadores, - criticava acerbo o sentimentalismo falso que seu Werther fizera brotar nos romances [...] É que os discípulos na fascinação da apoteose que erguem ao gênio, no tresladar, no arremedo de suas belezas, imitam-lhe também, e mais que o resto, os defeitos, porque foi no embelezá-los, em escondê-los sob flores, que os mestres envidaram suas forças (200o, p. 719). 
Com base nesse ponto de vista, Azevedo critica até mesmo Victor Hugo, escritor, como se sabe, de grande importância em sua poética, pois acredita que, sobretudo no drama, Hugo, assim como Alexandre Dumas, havia se rendido à fórmula do melodrama romântico, cujo sucesso de público era certo (AzEVEDo, 200o, p. 720-721).

Por conseguinte, Álvares de Azevedo avalia que, ao seguir o exemplo hugoano, a moderna escola dramática portuguesa só podia dar a lume dramas afetados, como eram os de "Mendes Leal, Abranches, Pereira da Cunha", o que o leva a lamentar-se "da afetação em geral de toda essa mocidade que desgarrou-se da simpleza de dizer do Sr. Almeida Garrett, e foi-se à cena falar às turbas uma língua que não era a dela" (AzEvEDo, 200o, p. 719).

Na breve passagem em que aborda o gênero lírico, sua crítica enfoca o problema da monotonia, a partir de um escritor particular, Mendes Leal: "Mas o que é de lamentar [...] da 'Rosa branca' e tanta poesia linda, é a pobreza de enredo, a monotonia das suas heroínas: é sempre a mesma beleza” (AzEvedo, 200o, p. 719-720). A estrofe do referido poema que Azevedo cita e os comentários feitos acerca dela faz com que suas opiniões possam ser pensadas como críticas ao ultrarromantismo, manifestação do movimento romântico dentro da qual ele é frequentemente alocado pela história literária. As imagens que são evocadas em "Rosa branca" lembram, de certo modo, aquelas que abundam nos poemas da primeira parte da Lira dos vinte anos:

O rosto um jaspe frio, um gelo imóvel

Em que vida não há,

E em formosura a triste inda primava,

Em lírio abatido,

Estátua q'rida d'escultor poeta,

Querubim perdido,

Sonho d'alma em noite melancólica,

Visão da madrugada,

Sem luz, sem cor - vestida de vapores,

De névoas coroada. ${ }^{8}$

Naqueles versos, segundo Azevedo, encontram-se

sempre as virgens alvas [...] Sempre as donzelas tristes como lírios pendentes ao peso da chuva [...]. Elas são todas belas, sim, mas belas de uma beleza monotipa; [...] tornam-se monótonas, porque o som mais doce, a sensação mais suave, se não mudar-se dela, arrefece-se e torna-se insípida (2000, p. 720).

8 Este poema foi publicado no $5^{\circ}$ volume da revista $O$ panorama, em 1841 e faz parte da Terceira estrofe. Ele encontra-se transcrito com exatidão no ensaio de Azevedo, à exceção do quarto verso, que seria "Ou querubim perdido"(apud AzEvedo, 2000, p. 720). 


\section{Posturas dissonantes}

A crítica aos excessos do romantismo é um grande ponto de aproximação entre Azevedo e Lopes de Mendonça, escritor algumas vezes tomado como ultrarromântico, mas que também rechaçou essa corrente. ${ }^{9}$ A partir da leitura de "Poesia e mocidade" e sobretudo d'“O Trovador", respectivamente o primeiro e o segundo entre os textos dos Ensaios de crítica e literatura, percebe-se que o jornalista português faz a crítica de um grupo particular de autores, ligados a' $O$ trovador, uma revista publicada por acadêmicos da Universidade de Coimbra, a partir de 1841, e que ficou conhecida como um marco da segunda geração romântica portuguesa, justamente a geração ultrarromântica. Paralelamente, quando se lê a crítica da literatura portuguesa contemporânea a Álvares de Azevedo, feita em "Literatura e civilização em Portugal”, nota-se que o brasileiro se circunscreve a esse mesmo grupo.

Mesmo que se coloque como amigo dos redatores d'O trovador, Mendonça assevera:

O principal defeito do Trovador, a meu ver, é estar encerrado numa escala muito limitada de sentimentos individuais. [...] É o eterno tema do amor, assimilado às opulentas emanações do mundo exterior: panteísmo de sentimento, aonde a idealidade às vezes se perde, nas divagações da descrição material [...].

Não manifestamos uma acusação, manifestamos apenas um fato. Para os engenhos moços, que ainda não simpatizaram com as grandes questões, em que se resolve a humanidade, que veem apenas no horizonte da vida uma mulher, bela como os seus sonhos encantados, é este o eterno canto, canto que nunca esmorece, que ressuscita todos os dias com o fervor de novas ilusões (1849, p. 175-176, grifo nosso).

Embora haja uma preocupação comum aos dois autores quanto à circunscrição da poesia a uma esfera muito restrita de imagens e sensações é, paradoxalmente, essa mesma crítica que parece afastá-los mais, já que a sua motivação pode ser distinta.

Como se viu na citação anterior, Mendonça crê que aqueles jovens ainda não tinham se debatido com as grandes questões, a saber: a liberdade, a igualdade,

9 Não há consenso absoluto sobre a aproximação de Lopes de Mendonça ao que se reconhece como ultrarromantismo. Sua recepção crítica já o compreendeu dessa maneira, caso das leituras de Jacinto do Prado Coelho (1947) e sobretudo a de José Augusto França (1974), porém, os estudos mais recentes vêm nuançando essa associação e ressaltando o pendor político dos seus escritos. Sérgio Nazar David, um dos estudiosos brasileiros que mais debateu a obra de Mendonça no Brasil, pondera que o estilo palavroso e por vezes exagerado do autor pode ter motivado essa aproximação, a qual considera equivocada, ainda mais tendo em vista o fato de tais características serem comuns ao período (apud Bonfim, 2013, p. 273). Para um balanço acerca dessas discussões, ver Bonfim (2013, p. 271-274). 
o progresso, a revolução. Assuntos candentes para um escritor imbuído por um ideário socialista ainda não exatamente estabelecido, mas que ele interpretava como fundamentalmente revolucionário (SÁ, 1964, p. 77) e, para quem, portanto, "travar a política com as questões literárias nem é um capricho de escritor (1849, p. 131)", é dever a ser encampado por toda a intelectualidade. Para o jornalista português, "a poesia é [...] não só um sublime exercício das faculdades do espírito, mas sobretudo um meio de influência social" $(1849$, p. 331) e, nesse sentido, ela é uma das ferramentas a serem utilizadas na revolução, "na emancipação das classes laboriosas" e na "solução dos problemas humanitários" (1849, p. 134).

Ele acredita, então, na instrução das camadas populares no sentido de uma conscientização que lhes permitisse reivindicar uma situação igualitária. Porém, Mendonça, proveniente ele mesmo dessas camadas, sabe que resolver esse problema não é simples, ainda mais quando se tem diante de si o quadro descrito por Victor de Sá, no qual nem os trabalhadores com quem o jornalista buscava dialogar em seus panfletos percebiam-se enquanto classe:

Não havendo ainda proletariado, nem consciência de classe operária, havia pelo menos, um profundo descontentamento popular, havia o sentimento de logro produzido pelo liberalismo, que afinal se limita a substituir uns barões por outros barões, os capitães-mores por caciques eleitorais, os antigos latifundiários eclesiásticos pelos donos laicos da riqueza, mas deixando na mesma todo o resto: o pobre sempre desamparado, o ofendido sem justiça, o trabalhador sem garantias de subsistência, saúde e instrução (SÁ, 1964, p. 72).

A par dessa insatisfação, Mendonça se coloca à esquerda dentro das correntes socialistas que se formavam àquela altura, negando o socialismo utópico como saída para o proletariado e vendo apenas na revolução a resposta definitiva aos males causados pelo capital, ideologia a qual ele defende em publicações como o Eco dos operários (SÁ, 1964, p. 78). Embora, segundo Jacinto Coelho do Prado, Lopes de Mendonça venha a relativizar, posteriormente, as imbricações entre arte e ideologia (1947, p. 253), pontuando que a arte tem uma certa independência, em 1849, certamente sob os influxos da chamada "primavera dos povos", cuja irrupção data de 1848, ele brada: "Já tivemos ocasião de dizer, em mais de um lugar: não acreditamos no dogma da arte pela arte" (1849, p. 331).

Tal orientação não aparece de forma clara em Álvares de Azevedo, cuja crítica parece residir mais numa esfera estética do que política, mesmo porque, caso vinculasse, de maneira mais explícita, poesia e ideologia, o jovem bacharel teria diante de si um cenário bastante distinto daquele que era combatido por Mendonça, já que nesse não figurava o trabalho escravo. De todo modo, cabe lembrar a definição de poesia proposta por Azevedo, no prefácio a outro poema de sua autoria, intitulado $O$ conde Lopo. Nesse texto de abertura, ele pontua: "O fim da poesia é o belo", a missão do poeta "é pois o apostolado da beleza, o dever de esfolhar coroas 
sobre todas as quadras da vida" (2000, p. 375), afirmando, mais à frente, que o fim da poesia romântica é a reunião de diversos tipos de belo (2000, p. 381), sendo a beleza passível de ser encontrada mesmo naquilo que é considerado imoral. Essa perspectiva desinteressada da arte sugere um diálogo com o prefácio à Mademoiselle de Maupin (1835), de Theophile Gautier, indicado por meio do trecho deste romance que serve de epígrafe a' $O$ conde Lopo.

Como é sabido, é nesse prefácio que Gautier, amparado pelas teorias kantianas, lança as bases da estética que ficou conhecida como "arte pela arte", e que veio a se acentuar no decorrer do século XIX, culminando em tendências formalistas como o parnasianismo e o simbolismo. O parágrafo final de "Literatura e civilização em Portugal” é outro momento no qual Azevedo parece aproximar-se dessa estética. Nele, o autor diz: "Portugal se mergulhara no crepúsculo. [...] A noite portuguesa, como as de verão, talvez não seja longa. Façam-na um serão de luar os trovadores de Coimbra. - Sim - Mas o que não poderão fazer é adiantar o dia” (200o, p. 744). Por meio dessa conclusão, quer nos parecer que Azevedo não considera a poesia capaz de realizar a missão que Mendonça lhe designa, ou, por outro lado, uma finalidade prática não deveria estar entre as preocupações de nenhum poeta, já que isso poderia acarretar prejuízo para elaboração artística.

\section{Conclusão}

Mesmo que Azevedo pareça se esquivar do pendor politicamente engajado que a poesia romântica poderia manifestar, a presença de Lopes de Mendonça em seus escritos e o valor que ele confere ao seu pensamento são significativos. Ela indica um movimento de apropriação reflexiva e consciente, que se situa na base da atividade de leitura empreendida pelo ensaísta brasileiro, uma vez que ele incorpora elementos presentes nos Ensaios de crítica e literatura que são pertinentes à elaboração de "Literatura e civilização e Portugal", descartando outros. Ou seja, as citações, por mais que sejam abundantes, cumprem uma função dentro do texto.

E, quando se resgatam as ideias que o poeta brasileiro defende enquanto orador de dois discursos, proferidos na Faculdade de Direito de São Paulo, é possível dizer que a missão regeneradora da poesia não está de todo excluída. Neles, poesia e revolução andam juntas, parceria que para Azevedo pode ser vista, por exemplo, em 1789 e 1830, na França:

Vede. A humanidade ergueu muita vez de sobranceria a fronte remoçada às caudais de luz, manadas dos cenáculos. Dessas turbas de irmãos que se vão as montanhas - como os discípulos, na escuridão das ladeiras inda vermelhas do Gólgota - passar as noites medonhas de barbaria aguardando as alvas das civilizações futuras; dessas comunidades de mancebos resvala sempre muita luz de esperança, muita auréola de claridão. Daí se erguem muitas frontes pálidas, onde fundo borbulha o gênio, abatidas 
como ao peso de nuvens ardentes, ofuscadas como as evocações fantásticas das agoniadas iniciações do apostolado - e que inda febris daquelas desoras em que as visões correm descabeladas e sanguentas, como as rondas lívidas de Holbein - sonham - e criam as revoluções de 1789 e 1830. O carro do progresso porque rode há mister do impulso daquela onda perfumosa que se acorda iriante aos sonhos do poeta, às lucubrações da filosofia (AZEVEDo, 20oo, p. 761-762).

Dessa maneira, talvez se possa dizer que, como um escritor preocupado em manter aberto uma multiplicidade de diálogos críticos e estéticos, característica, aliás, própria do romantismo, compreendido enquanto modernidade (PAZ, 2013, p. 16), Álvares de Azevedo não deixe de flertar com essa outra tendência, mesmo que num segundo plano, a ser talvez desenvolvido em uma outra "quadra da vida", na expressão de Mendonça.

De uma forma ampla, pode-se assinalar que é do interior mesmo da vertente ultrarromântica que emergem seus críticos (Azevedo, Mendonça e Camilo, entre outros), o que aponta tanto para a capacidade de autocrítica do movimento, fomentada pela ironia romântica, quanto para o delineamento de uma possível bifurcação dessa crítica. Tal bifurcação pode ser pensada, conforme a discussão proposta neste artigo, em função da estética da "arte pela arte", separando estetas e engajados.

\section{Referências}

Azevedo, Álvares de. Obras completas. Organização de Alexei Bueno. Rio de Janeiro: Nova Aguilar, 2000.

Barboza, Onédia Célia de Carvalho. Byron no Brasil: traduções. São Paulo: Ática, 1975 .

Bonfim, Julianna de Souza Cardoso. As recordações de Itália (1852 - 1853), de A. P. Lopes de Mendonça: uma obra política - Edição e estudo crítico. Dissertação (Mestrado em Letras) - Universidade Estadual do Rio de Janeiro, Rio de Janeiro, 2013.

Broca, José Brito. Românticos, pré-românticos, ultra-românticos: vida literária e romantismo brasileiro. São Paulo: Polis, 1979.

CAmilo, Vagner. Risos entre pares: poesia e humor românticos. São Paulo: Edusp; Fapesp, 1997.

CANDido, Antonio. Formação da literatura brasileira: momentos decisivos (17501880). 10. ed. Rio de Janeiro: Ouro Sobre Azul, 2006.

CAndido, Antonio. Literatura comparada. In: CANDido, Antonio. Recortes. São Paulo: Companhia das Letras, 1993. p. 211-215. 
Cunha, Cilaine Alves. O belo e o disforme: Álvares de Azevedo e a ironia romântica. São Paulo: Edusp; Fapesp, 1998.

Cunha, Cilaine Alves. Palpites dissonantes de brasileirismo em 'Literatura e civilização em Portugal'. Literatura e autoritarismo, Santa Maria, n. 4, 2001, p. 15-26.

David, Sérgio Nazar. A. P. Lopes de Mendonça e o jornal A Revolução de Setembro. In: Neves, Lúcia Maria Bastos Pereira das et al. (Org.). Literatura, história e política em Portugal (1829-1856). Rio de Janeiro: Eduerj, 2007. p. 189-194.

DAvid, Sérgio Nazar. Paixão e revolução na obra de A. P. Lopes de Mendonça. In: Souza, Roberto Acizelo de; Holanda, Silvio Augusto de Oliveira; Augustr, Valéria (Org.). Narrativa e recepção: séculos XIX e XX. Rio de Janeiro: De Letras; Niterói: EdUFF, 2009. p. 159-186.

FARIA, Maria Alice de Oliveira. Astarte e a espiral: um confronto entre Álvares de Azevedo e Alfred de Musset. São Paulo: Conselho Estadual de Cultura, 1973.

GinzBurg, Jaime. História e melancolia em Literatura e civilização em Portugal. Estudos Portugueses e Africanos, Campinas, n. 33/34, p. 21-27, jan./dez. 1999.

Mendonça, António Pedro Lopes de. Ensaios de critica e litteratura. Lisboa: Typ. da Revolução de Septembro, 1849.

MendonçA, António Pedro Lopes de. Memorias de litteratura contemporanea. Lisboa: Typ. do Panorama, 1855 .

Moreira, Maria Eunice. Três românticos brasileiros e a crítica portuguesa no século XIX. Miscelânea, Assis, v. 14, p. 69-79, jul./dez. 2013. Disponível em: https: //goo.gl/mxUHoA. Acesso em: 27 fev. 2017.

PAz, Octavio. Os filhos do barro: do romantismo à vanguarda. Tradução de Ari Roitman e Paulina Wacht. São Paulo: Cosac Naify; Fondo de Cultura Económica, 2013.

PIREs, Maria da Natividade; REIS, Carlos. História crítica da literatura portuguesa: o romantismo. Lisboa: Verbo, 1993. v. 5 .

Prata, Manuel Alberto Carvalho (Org.). A imprensa estudantil em Coimbra. v. I: Repertório Analítico (século XIX). Coimbra: Imprensa da Universidade, 2006.

SÁ, Victor de. A primeira imprensa socialista em Portugal. In: SÁ, Victor de. Perspectivas do século XIX: ensaios. Lisboa: Portugália, 1964. p. 69-196.

SAntos, Natália Gonçalves de Souza. Um leitor inconformado: Álvares de Azevedo e o periodismo do século XIX. Tese (Doutorado em Letras - Teoria Literária e Literatura Comparada) - Universidade de São Paulo, São Paulo, 2018.

Recebido em 10 de abril de 2018. 
Aprovado em 19 de novembro de 2018.

\section{Resumo/Abstract/Resumen}

\section{A literatura romântica portuguesa sob o olhar de Álvares de Azevedo e} Lopes de Mendonça: diálogos críticos

\section{Natália Gonçalves de Souza Santos}

O ensaio "Literatura e civilização em Portugal", de Álvares de Azevedo, divide a história literária portuguesa em duas fases que já vêm designadas em seu próprio título: a heroica, dedicada a Ferreira e Camões, e a negra, circunscrita a Bocage. Porém, para além do cânone já estabelecido, Azevedo faz um importante comentário, embora panorâmico, sobre aquilo que havia de mais recente no cenário literário português em torno de 1850 . E, para isso, recorre aos escritos também recentes de um crítico contemporâneo, Lopes de Mendonça, e seus Ensaios de crítica e literatura (1849), coligidos de uma publicação anterior no periódico A Revolução de Setembro. A leitura feita pelo ensaísta brasileiro sinaliza, em uma geração literária cujo interesse se voltava notadamente para França e Inglaterra, a manutenção dos diálogos entre portugueses e brasileiros, mesmo após a independência política do Brasil e a pretendida ruptura proveniente dela. Assim, este artigo pretende analisar pontos de contato e dissonância entre as posições dos dois autores diante do romantismo português, a partir da leitura que Azevedo faz de Mendonça, cujo pensamento crítico foi marcado por um socialismo exacerbado e pela condenação dos excessos do ultrarromantismo.

Palavras-chave: Álvares de Azevedo, Lopes de Mendonça, romantismo português.

The romantic literature from the perspective of Álvares de Azevedo and Lopes de Mendonça: critical dialogues

\section{Natália Gonçalves de Souza Santos}

The essay "Literatura e civilização em Portugal", by Álvares de Azevedo, divides the Portuguese literature history in two phases that are already designated by their own titles: the heroic, dedicated to Ferreira and Camões, and the dark, circumscribed to Bocage. Nevertheless, beyond the canon previously established, Azevedo made an important comment, although panoramic, about the most recent works in the Portuguese literature scenario around 1850. And, for that, he turns to the writings, also recent, of a contemporaneous critic, Lopes de Mendonça, and to his Ensaios de crítica e literatura (1848), collected from a previous publication on the periodical A Revolução de Setembro. The reading done by the Brazilian essayist signalizes, on a literary generation whose interest was mainly 
towards France and England, the maintenance of the dialogue between the Portugueses and the Brazilians, even after the political independence of Brazil and the intended rupture resulting from it. Therefore, this article intends to analyse the touch points and the dissonances between the positions of both authors about the Portuguese romanticism, based on how Azevedo reads Mendonça's works, whose critical thought was mainly featured by an exacerbated socialism and by the disapproval of the excesses of the ultra romanticism.

Keywords: Álvares de Azevedo, Lopes de Mendonça, Portuguese romanticism.

\section{La literatura romántica portuguesa bajo la mirada de Álvares de Azevedo} y Lopes de Mendonça: diálogos críticos

\section{Natália Gonçalves de Souza Santos}

El ensayo "Literatura e civilização em Portugal", de Álvares de Azevedo, divide la historia literaria portuguesa en dos fases que son ya designadas en el propio título: la heroica, dedicada a Ferreira y Camões; y la negra, circunscrita a Bocage. Sin embargo, más allá del canon establecido, Azevedo hace un importante comentario, aunque panorámico, sobre las obras más recientes en el escenario portugués del año 185o. Para ello, vuelve sobre los escritos también recientes de un crítico contemporáneo suyo: Lopes de Mendonça y sus Ensaios de crítica e literatura (1849), reunidos de una publicación anterior en el periódico A Revolução de Setem$b r o$. La lectura hecha por el ensayista brasileño señala, en una generación literaria cuyo interés se volvía especialmentemente hacia Francia e Inglaterra, el hecho de la conservación del diálogo entre portugueses y brasileños, aun después de la independencia política de Brasil y la supuesta ruptura originada. Así pues, este artículo pretende analizar los puntos de contacto y las disonancias entre las posiciones de los dos autores ante el romanticismo portugués, a partir de la lectura que Azevedo hace de Mendonça, cuyo pensamiento crítico estuvo marcado por un socialismo exacerbado y por la condenación de los excesos del ultrarromanticismo.

Palabras clave: Álvares de Azevedo, Lopes de Mendonça, romanticismo portugués. 